\title{
Discussion: Strength of steel fibre reinforced concrete ground
} slabs

\section{S. Chen}

\section{W. Elsaigh, University of Pretoria}

In Professor Chen's paper a physical model slab, measuring $2000 \times 2000 \times 120 \mathrm{~mm}$, is used to assess the accuracy of theoretical models usually employed for the design of such slabs. Accordingly, the model developed by Shentu et al (i.e. the formula presented as equation (9) of the paper) is found to provide a better prediction. In my opinion the following aspects must be considered when using a model slab to validate design formulae used to design real-life floor slabs.

Lack of edge restraint in the model slab tested allows the slab to lift up from the underlying layers, which is not the case for a real floor slab normally restrained by another slab at the joints. There are two aspects associated with this lifting phenomenon.

(a) The mechanism of collapse differs from that expected for real floor slabs (fan type of failure).

(b) It must be emphasised that the lifting at the edges and corners of the model slab during the experiment would cause a redistribution of the moments and forces. Therefore a model slab will yield a higher load compared to a real floor slab.

Looking at Fig. 4. (p. 159), the deflection corresponding to the ultimate load for model slabs DS1 and DS2 is about $8 \mathrm{~mm}$. In my opinion this deflection value is too high and can damage the underlying layers if these ultimate loads are used to design real floor slabs. Consequently, we are not only interested in the ultimate load but also in the deflection corresponding to this ultimate load. Therefore with deflection also being a crucial aspect, a deflection limiting criteria is required for the design of these ground slabs.

One could argue that, according to the limit-state theory, this ultimate load will be divided by a safety factor and the deflection corresponding to the calculated design load will be in the range of the so-called 'acceptable deflection'. However, according to the limit state, we must accept that a structural element is cracked, which is unacceptable for floor slabs. We can only accept the slab being cracked at the bottom but we can not accept it if the crack extends to the top. Thus it is a different design philosophy.
The Meyerhof formula might still be valid for the design of floor slabs although it does not provide a model to calculate deflection at the calculated ultimate load.

\section{Author's reply}

There should be some differences between the model slabs and the real-life ground-floor slabs which might influence the final strength of the slabs. However, based on the elastic and the ultimate analysis by Losberg, ${ }^{6}$ these effects should be minimised when the size of a slab satisfies the stiffness requirement; that is, $R_{\mathrm{b}}>3 L_{\mathrm{k}}$ in the elastic stage and $R_{\mathrm{b}}>$ $1.9 L_{\mathrm{k}}$ in the plastic stage concerning flexural failure in the slab, where $R_{\mathrm{b}}$ is the radius of the slab, and $L_{\mathrm{k}}$ is the radius of relative stiffness of the slab. It was also discussed by Meyerhof ${ }^{11}$ that the solution of the load-carrying capacity of simply supported and fixed ideally-plastic circular plates (slabs) under central concentrated loads which is extended to plates (slabs) on a discontinuous-elastic foundation is independent of the size and boundary conditions of the plate as far as the slab material obeys the Mises yield condition. So that in most test investigations on ground slabs, the sample slabs with limited transverse sizes were used to simulate real-life ground-floor slabs which may have greater length in the corresponding directions and with different edge restraints.

Based on equation (3), the radius of relative stiffness of the sample slabs is about $540 \mathrm{~mm}$, the width of the slabs is slightly less than $1.9 L_{\mathrm{k}}$, and the width of the slabs tested by Beckett ${ }^{2}$ is between 1.9 and $2.2 L_{\mathrm{k}}$. From Table 5, it can be seen that the ratios of $P_{\mathrm{t}} / P_{\mathrm{u} 2}$ are slightly higher by the author's test than those of Beckett's specimens.

In design and construction practice, thickness design is widely accepted for its simplicity, which is based on the simple plastic analysis of the ground slabs. It is a good question to evaluate the deflection of a ground concrete slab. It would be a crucial aspect to limit the deflection of the slab, and questions may also arise as to what acceptable deflection criteria should be used for different sub-layer materials. In current Chinese practice, the strength of the sub-base layer or the sub-base is checked to ensure its safety other than to limit its deflection. Further research may be required to interpret the interactive load-deflection behaviour between the ground slab and the underneath sub-base. At the ultimate load, as defined when the 
cracks developed through the full depth of the slab in the paper, the deflections are $6.62 \mathrm{~mm}$ and $6.22 \mathrm{~mm}$ for slabs DS1 and DS2 respectively (given in Table 2 ).

Test investigations revealed that for plain concrete ground slabs, after initial radial cracks occur at the bottom of a slab, the slab can be subject to substantial incremental loading before the cracks develop throughout the full depth of the slab and join the circumferential tension cracks at the top. This is the ultimate strength state of a ground concrete slab defined in the Chinese Code for ground construction practice. When reinforced with steel fibres, concrete ground slabs behave in a predictably ductile manner. Thus it is reasonable to evaluate the strength of the slab accepting the cracks developing through the full depth of the slabs.

More sophisticated models to simulate the unilateral contact between the slabs and the underneath sub-base can be found in recent literature by Cerioni and Mingardi, ${ }^{10}$ and Barros and Figueiras ${ }^{12}$ which are based on non-elastic finite-element analysis. Their predictions of the load-deflection behaviour of ground reinforced concrete slabs agree well with test results. However, the Meyerhof formula should be still versatile for assessing the loading capacity of a ground slab because it provides more scenarios of load conditions than just a central concentrated load on the slab.

\section{REFERENCES}

11. MeYerhof, G. G. Bearing capacity of floating ice sheets. Journal of the Engineering Mechanics Division, ASCE, 1960, 86, No. 5, 113-145.

12. Barros, J. A. 0. and Figueiras J. A. Model for the analysis of steel fibre reforced concrete slabs on grade. Computers Et Structures, 2001, 79, No. 1, 97-106.

\section{ERRATUM}

Please note that equation (3) should read

\begin{tabular}{|l|l|}
\hline 3 & $L_{k}=\left(\frac{E h_{\mathrm{s}}^{3}}{12(1-v) k_{\mathrm{s}}}\right)^{0 \cdot 25}$ \\
\hline
\end{tabular}

